Даньшин Александр Владимирович

кандидат юридических наук, доцент, заведующий кафедрой теории и истории государства и права Кемеровского института (филиал) Российского экономического университета имени Г.В. Плеханова

\section{«РУКОВОДСТВА ДЛЯ СУДЕЙ» В ИМПЕРАТОРСКОМ КИТАЕ: ПОИСК КОМПРОМИССА МЕЖДУ ТЕОРИЕЙ И ПРАКТИКОЙ СУДЕБНОГО ПРОЦЕССА}

\begin{abstract}
Аннотация:
Статья посвящена сравнительному анализу юридических комментариев частных лиц к судебным делам периода императорского Китая. Эти «руководства для судей» пользовались у китайских чиновников большой популярностью, являясь ценным пособием при рассмотрении ими уголовных и гражданских дел. В отличие от официальных изданий, которые давали теоретическую картину функционирования судебной системы, эти пособия показывали, какой она является на самом деле. Основное внимание уделяется исследованию по судебно-медицинской экспертизе XIII 6. «Руководство по вымыванию несправедливости» ("Си юань лу»), сборнику комментариев сунского автора Чжэн Кэ «Волшебное зеркало для решения [судебных] дел» («Чжэ юй гуй цзянь») и работе минского автора Люй Куня "Опыт практического управления» («Ши чэнь лу»). В этих работах давались практические рекомендации по всем этапам судебного разбирательства (дознание, расследование, арест, судебное слушание, допрос, принятие судебного решения, отправка отчета в вышестоящие инстанции и др.), которые проиллюстрированы яркими примерами реальных или вымышленных судебных дел. Анализируя институт применения пыток в судебном процессе, автор приходит к выводу, что «руководства для судей» не придерживаются так называемой «формальной теории доказательств" и не считают признание под пыткой «царицей доказательств».
\end{abstract}

Ключевые слова:

право императорского Китая, «руководства для судей», судебный процесс, социальная гармония.
Danshin Aleksandr Vladimirovich

PhD in Law, Associate Professor, Head of the Department of Theory and History of State and Law, Kemerovo branch of Plekhanov Russian University of Economics

'GUIDELINES FOR JUDGES' IN IMPERIAL CHINA: FINDING A COMPROMISE BETWEEN THEORY AND PRACTICE OF LEGAL PROCEEDINGS
Summary:

The author provides a comparative analysis of individuals' legal comments on criminal cases in China's imperial period. These 'guidelines for judges' were very popular among Chinese officials and were a valuable tool to handle criminal and civil cases. In contrast to the official publications characterizing the judicial system functioning, these guides described the real situation in Chinese legal proceedings. The paper focuses on the studies of the 13th-century forensic medical examination: 'Instructions to Coroners' (Hsi yüan lu), 'Magic Mirror for Deciding Cases' (Zhe yu gui jian), the commentaries provided by the Song dynasty writer Zheng $\mathrm{Ke}$, and 'Record of Practical Administration' (Shihcheng lu) by the Ming dynasty writer Lü K'un. The authors of these works made practical recommendations on all stages of legal proceedings (inquiry, investigation, arrest, court hearing, interrogation, decision-making, reporting to higher authorities) exemplified by real or fake criminal cases. Analyzing the institution of torture in legal proceedings, the author concludes that the 'guidelines for judges' fail both to adhere to the socalled formal theory of evidence and to regard torture as the queen of evidence.

Судебная власть в императорском Китае (история которого простирается от периода правления первого китайского императора Цинь Шихуанди в III в. до н. э. до падения монархии в Китае в 1911 г. при последнем ее императоре Пу И) не была отделена от других ветвей власти, являясь одной из нескольких наиболее важных функций гражданских и военных чиновников различного уровня, занимавшихся сбором налогов и надзором за зернохранилищами, организацией общественных работ и официальных церемоний и др. На протяжении всей своей карьеры чиновники постоянно переводились на новые должности и начинали испытывать острую необходимость в получении глубоких юридических знаний, которых у них, как правило, никогда и не было, поскольку на специальных экзаменах, открывавших путь к государственной службе, от соискателей требовалось прежде всего знание основных классических конфуцианских текстов, объединенных в «Пятикнижие» («У-цзин») и «Четырехкнижие» («Сы-шу»), на основе которых они должны были написать развернутое эссе [1, с. 154-158]. Главной задачей экзаменов было выявление высоких морально-этических качеств соискателей, что считалось существенно более важным, чем какие- 
либо практические навыки или юридические знания, которые, как представлялось, можно было приобрести уже в процессе государственной службы.

Не обладая специальными юридическими знаниями, чиновники тем не менее отвечали за организацию всех необходимых процессуальных мероприятий по расследованию правонарушений в уголовной, административной и гражданско-правовой сферах, в том числе единолично принимали по таким делам судебные решения. Для того чтобы они не допускали юридических ошибок, государством периодически публиковались официальные справочники и комментарии к различным сборникам законов. C XIII в. широкое распространение получают написанные частными лицами юридические труды, среди которых наибольшей популярностью пользовались сборники комментариев к реальным или вымышленным судебным делам, а также пособия для чиновников по осуществлению ими судебных полномочий, которые обобщенно можно назвать «руководствами (пособиями) для судей». В отличие от официальных изданий, в большей степени дающих теоретическую картину функционирования судебной системы, эти пособия, авторами которых являлись, как правило, бывшие высокопоставленные чиновники, показывали, какой она является на самом деле в процессе ее практического функционирования.

После образования в 1949 г. Китайской Народной Республики и открытия затем центральных и местных архивов ученые различных стран получили возможность глубокого изучения этих материалов. Однако в отечественной исторической и историко-правовой науке определенное внимание уделялось лишь исследованию по судебно-медицинской экспертизе сунского автора Сун Цзы (1186-1249) «Руководство по вымыванию несправедливости» («Си юань лу»), в то время как о других документах можно найти лишь отдельные упоминания. В связи с этим в данной статье ставится задача впервые познакомить российского читателя с основным содержанием некоторых других «руководств для судей», проведя при этом их сравнительный анализ. Наиболее известными среди них, кроме «Си юань лу», был опубликованный в 1211 г. и представляющий из себя собрание отчетов по 144 судебным делам труд Гуй Ваньжуна «Аналогичные случаи под сенью грушевого дерева» («Тан инь би ши»), сборник судебных случаев с комментариями сунского автора Чжэн Кэ «Волшебное зеркало для решения [судебных] дел» («Чжэ юй гуй цзянь»), работа минского автора Люй Куня (Люй Синьу) (1536-1618) «Опыт практического управления» («Ши чэнь лу»), сборник судебных дел «Обзор параллельных случаев» («Син ань хуэй лань») и др. Эти материалы, при отсутствии в традиционном Китае специального процессуального законодательства, были незаменимыми источниками юридических знаний как при расследовании уголовных преступлений, так и в процессе рассмотрения так называемых «второстепенных дел», т. е. гражданских исков по семейным, брачным и земельным вопросам.

Имея схожую логическую последовательность в изложении вопросов судебной процедуры, эти руководства отличались друг от друга тем, что в одних основное внимание уделялось воспитательно-морализаторским рекомендациям чиновникам при осуществлении ими процессуальных действий. В других руководствах, также не забывая говорить о том, что судья во всем должен следовать конфуцианским принципам поведения «благородного мужа» (цзюньцзы), авторы считали своей главной задачей дать как можно больше практических советов по всем этапам судебного разбирательства (дознание, расследование, арест, судебное слушание, допрос, принятие судебного решения, отправка отчета в вышестоящие инстанции и др.), иллюстрируя все это примерами реальных или вымышленных ими судебных дел. Среди первого типа сочинений особый интерес представляют комментарии Чжэн Кэ, ярким же примером работ более утилитарного характера являются труд Люй Куня и руководство по судебно-медицинской экспертизе «Си юань лу», причем последнее, в отличие от первых двух, было официально рекомендовано властями для его практического использования в судебной деятельности чиновников [2, p. 68, 73].

Наибольшее внимание в руководствах уделяется тяжким преступлениям (убийства, грабежи, разбои, изнасилования и др.), при этом предлагается придерживаться нескольких основных правил. Прежде всего, начинать расследование незамедлительно, поскольку промедление существенно затруднит поиск свидетелей и предоставит заинтересованным лицам возможность согласовать свои показания или подкупить свидетелей. Исключениями из этого правила может быть только болезнь чиновника или его крайняя занятость другим важным делом, но в любом случае он обязан был поручить расследование кому-либо из своих помощников, чтобы, например, судебно-медицинскую экспертизу, в соответствии с требованием «Си юань лу», провести не позднее двух часов с момента получения информации об убийстве [3, р. 34-35]. Крайне неприятную процедуру по осмотру и экспертизе трупа, что являлось обязательным элементом в расследовании убийства (или предполагаемого убийства), не рекомендовалось доверять своим подчиненным [4, с. 46] (клеркам, посыльным, полицейским), низкая заработная плата которых вынуждала их вымогать взятки, а поскольку они постоянно думали о наградах и повышении по 
службе, то «больше заботились о статистике, чем о справедливости» [5, р. 58]. Даже если помощники судьи имели хорошие медицинские навыки, судья не должен забывать о том, что за халатность в проведении судебно-медицинской экспертизы уголовную ответственность несет именно он [6]. Заметной особенностью таких экспертиз являлось то, что вскрытие мертвых тел (за исключением изучения костей уже сгнивших останков) никогда не проводилось и внутренние органы не исследовались, а все выводы делались исходя только из самого тщательного внешнего осмотра тела [7].

В трактате «Си юань лу» подробнейшим образом поясняется, как необходимо проводить осмотр тела, чтобы выяснить, от чего человек умер: от ножевых ран или ран, нанесенных руками или ногами, от утопления или удушения, от отравления или ошпаривания, от удара о камень или сексуальных излишеств. Особенно много внимания посвящается тому, как отличить насильственную смерть от самоубийства или инсценировки убийства, обращая внимание на необходимость изучения самых, казалось бы, незначительных повреждений или изменений на теле человека, а также серьезному изучению одежды потерпевшего или орудий преступления, подкрепляя важность этого поговоркой о том, что «отличие в один волос приведет к разнице в тысячу ли» [8, p. 86].

В то же время, наряду с подробным описанием различных объективных признаков, позволявших во всем этом разобраться, авторы руководств подсказывали, каким образом, проявив смекалку, потратить значительно меньше времени на необходимые исследования. Например, при необходимости выявления невидимых следов крови на металлическом орудии убийства его нужно «нагреть докрасна на древесном угле и залить сильным уксусом». Приводится пример из судебной практики, позволивший из большого количества предметов исследования сразу выбрать нужный: «Когда судья определил, что ранения нанесли серпом, а некий человек поссорился с умершим из-за долга, он пошел в деревню, где жил подозреваемый, приказав всем положить свои серпы на землю. Через некоторое время он обратился к подозреваемому мужчине и обвинил его в убийстве. Тот отрицал свою вину, но чиновник указал на рой мух, которые, привлеченные запахом крови, выбрали именно его серп среди семидесяти других, и убийца признался» [9]. Экспертиза определила наличие следов крови на серпе, подтвердив тем самым вывод судьи и признательные показания подозреваемого.

Говоря о половых преступлениях, руководства обращают внимание на то, что по таким делам «достаточно просто сфабриковать ложные обвинения и довольно трудно прояснить ситуацию», поскольку «нельзя знать наверняка, не муж ли заставляет свою жену [подать заявление], чтобы ложно обвинить кого-то [в сексуальных домогательствах], и очень сложно выяснить, не сама ли женщина заинтересована в этой авантюре с целью получения [какой-либо] выгоды», и поэтому советуют чиновникам воздерживаться от принятия заявлений по таким делам, особенно если это касается простых людей, не отличающихся моральной чистотой [10]. Авторы руководств, по нашему мнению, подводят читателей к выводу о том, что такие дела нужно постараться передавать на рассмотрение семьи или клана, хотя прямо об этом и не говорят.

При осуществлении судебного разбирательства руководство неоднократно указывает чиновникам на необходимость строгого соблюдения процессуальных сроков и, независимо от возможных затруднений при осуществлении ареста и расследования, завершать разбирательство в течение трех месяцев. Указывается также на обязанность чиновника «выслушать заявителя в тот же день, когда он обратился к властям, и, даже если [чиновник] очень занят, срок, в течение которого человек будет ожидать [когда его выслушают], не должен превышать двух дней». Рекомендуется вышестоящему начальству отмечать каждый факт нарушения процессуальных сроков в послужном списке судьи. Кроме этого, автор предупреждает о необходимости быть готовыми к противодействию в судах недобросовестной деятельности так называемых «исковых мастеров» или «обманщиков тяжб» (сун шu). Как правило, это бывшие работники местных органов власти, которые знакомы с лазейками в законах и судебной системе и за деньги готовы любому предложить свои услуги по составлению ложного иска. Таким лицам необходимо в открытом судебном заседании давать твердый отпор, чтобы в дальнейшем у них отпало желание обращаться именно к этому судье, который, с одной стороны, покажет всем свою компетентность, с другой - не будет впустую тратить время на рассмотрение явно вымышленного иска, результатом которого может быть только личное обогащение «искового мастера» за счет своего обманутого клиента [11]. Чтобы люди меньше обращались к таким специалистам, а также для более слаженной организации работы судов, многие руководства предлагают уже готовые формы различных исков и заявлений.

Что касается принципов оценки доказательств в судебном процессе, тексты «руководств для судей» говорят о том, что их авторы далеки от так называемой «формальной теории доказательств» с ее строгой иерархией различных видов доказательств. Несмотря на то что в Китае по закону «никто не мог быть объявлен виновным в преступлении, в котором он не признался» [12, 
р. 103], они настаивают на том, что признание нужно считать лишь фрормальным условием, позволяющим судьям вынести обвинительный приговор, который должен быть основан на совокупности самых различных доказательств (показания свидетелей, судебно-медицинская экспертиза, документы и др.). В руководствах подчеркивается, что признание обвиняемого хотя и необходимо, однако недостаточно для его осуждения, поскольку люди нередко берут на себя вину, лишь бы только прекратились пытки, которым они подвергались [13].

Не исключая тем не менее применения в судебном процессе пыток, возникающее в связи с этим противоречие между буквой закона и убеждениями авторов «руководств для судей», они предлагают следующий компромисс: 1) назначать пытку только при расследовании тяжких преступлений, 2) применять пытку только тогда, когда другие доказательства (прежде всего свидетели) уже фактически изобличили преступника, но он отказывается признавать свою вину; 3) использовать в процессе «пытки путем избиения» только бамбуковые или деревянные палки официально установленного размера и веса; 4) не превышать при избиении максимально разрешенное количество ударов (легкими палками - 50 ударов, тяжелыми - 100 ударов); 5) «пытку путем сжатия пальцев» деревянными брусками проводить только на двух пальцах и не более двух часов; 6) не применять пытку более одного раза, в то время как официальные кодексы разрешают повторять ее трижды [14, с. 181-184]; 7) полностью исключить применение стягивающих голову обручей; 8) не считать пытку основным способом получения признания, избегая, насколько это возможно, ее применения [15]. В этих рекомендациях можно увидеть кардинальное отличие института пытки в судебной системе традиционного Китая и средневековой Европы, где многие столетия непререкаемым авторитетом пользовались сочинения, подобные «Молоту ведьм», «Каролины» и др., считавшие «царицей доказательств» признание под пыткой, без которого, как правило, нельзя было вынести обвинительный приговор.

Если же объективных доказательств было недостаточно, авторы китайских руководств рекомендуют вместо пыток использовать различные уловки как способы получения таких доказательств. В качестве примера такой уловки говорится о судье, который, расследуя заявление о краже лука, вызывал к себе по очереди жителей села, делая вид, что делает свои умозаключения по «пяти видам наблюдений», перечисленным еще в древнейшем памятнике китайской литературы «Чжоу ли»: по наблюдению за словами, за выражением лица, за дыханием, за реакцией на вопросы и поведение окружающих. Вскоре, поразив всех окружающих своими уникальными способностями, он безошибочно назвал имя преступника, хотя это был лишь спектакль, который был затеян для того, чтобы во время опроса сельчан выяснить, от кого из них пахнет луком, и значительно сузить список подозреваемых [16].

В то же время, анализируя популярные литературные произведения, авторы руководств обращают внимание читателей на то, что далеко не все приводимые там примеры следует применять на практике. Если притчи, подобные той, когда женщинам предлагают перетянуть на свою сторону новорожденного ребенка, которого каждая называла своим, они считали вполне допустимыми в работе судей, другие истории могут лишь свидетельствовать о некомпетентности писателей, от советов которых нужно держаться подальше. В подтверждение этого приводится сюжет из известного литературного произведения, в котором одного из двух малолетних детей, играющих вместе на рынке, насмерть затоптала лошадь. Обе матери горячо убеждают судью, что выживший ребенок именно ее. Поскольку доказательств оказалось недостаточно, судья театрально приходит в раздражение и, заявив женщинам, что если бы лошадь затоптала обоих детей, то они все равно бы ссорились, приказывает своему помощнику бросить выжившего ребенка в колодец. Та женщина, которая предприняла отчаянную попытку вырвать ребенка из рук чиновника, и была признана матерью. Казалось бы, этот рассказ принципиально не отличается от предыдущего, однако в этом случае он является лишь «приукрашенной чепухой несведущих людей» [17]. Ведь внимательный судья сразу же должен был понять, что, в отличие от классического примера «соломонова суда», где речь шла о новорожденных детях, в данном случае самостоятельно играющие на рынке дети не могли быть меньше двух- или трехлетнего возраста и, несомненно, узнали бы своих матерей, как только бы увидели их. Автор подчеркивает, что такие выдуманные истории могли создавать у судей впечатление, что исключительно силой своей интуиции и особой прозорливости можно без особого труда раскрыть любое преступление, в то время как для этого требуется большая работа по поиску неопровержимых объективных доказательств.

Одной из самых неожиданных рекомендаций, которая встречается во многих руководствах, является совет не бояться в своих решениях отклоняться от буквы закона, полагаясь в ряде случаев на собственный опыт и здравый смысл. Особенно если речь идет о смертной казни, судья должен искать любые правомерные причины, чтобы уйти от такого наказания, хотя оно и закреплено в законе, а в том случае, если сам император намеревается вынести несправедливый приго- 
вор, не бояться высказывать ему свое несогласие, даже если дело касается человека неблагородного сословия [18]. И хотя для этого требуется определенная смелость и зачастую гораздо больше времени и сил, чем формальное и «слепое» следование требованиям законодательства, такие решения судьи, по мнению авторов руководств, больше соответствуют представлениям людей о справедливости и повысят не только его личный авторитет, но и доверие к власти в целом.

Авторы руководств не только на словах говорили о торжестве принципа справедливости, но и личным примером отстаивали свои убеждения. Люй Кунь, например, за неоднократную критику решений императора в процессуальной сфере, которые, по его мнению, противоречили моральным принципам конфуцианства, был обвинен в нарушении служебной этики и освобожден от должности [19]. Подобные фракты еще больше поднимали авторитет «руководств для судей», о растущей популярности которых среди китайских чиновников говорит хотя бы тот фракт, что они постоянно переиздавались и занимали не последнее место в их личных библиотеках. Изучение этикоправовых традиций конфуцианства, по мнению современных китайских авторов, и в настоящее время имеет важное практическое значение «для повышения моральных качеств судей в России и Китае», так как без нравственных начал невозможно «истинное правосудие» [20, с. 17-18].

Таким образом, сравнительный анализ наиболее известных «руководств (пособий) для судей» периода императорского Китая позволяет прийти к следующим основным выводам:

- при отсутствии в традиционном Китае кодифицированного процессуального законодательства, а также системы специального юридического образования рассматриваемые «руководства для судей» были для китайских чиновников важными источниками знаний в этой области;

- оставаясь весьма влиятельными вплоть до падения последней в Китае императорской династии Цин (1644-1911), такие пособия пользовались у китайских чиновников большой популярностью, являясь ценным пособием при рассмотрении ими как уголовных, так и гражданских дел;

- авторы руководств настоятельно рекомендовали судьям не доверять своим подчиненным (даже имеющим специальную подготовку) проведение различных процессуальных действий, поскольку они, в отличие от самих судей, не являются «благородными мужами» (цзюньцзы) и больше думают о своей личной выгоде;

- для сокращения времени и экономии средств при проведении судебных разбирательств руководства советуют чиновникам не принимать составленные «обманщиками тяжб» (сун ши) явно не обоснованные жалобы, а также не бояться идти на различные уловки типа «соломонова суда» или показного проявления якобы уникальных способностей судьи;

- в отличие от процессуального законодательства во многих европейских странах классического и позднего Средневековья, считавшего признание под пыткой «царицей доказательств», китайские руководства такое признание не рассматривали как достаточное для вынесения обвинительного приговора;

- авторы частных комментариев призывали судей отходить в своих решениях от положений закона, когда они противоречили конфуцианским представлениям о справедливости, что, по их мнению, не только укрепляет в государстве авторитет судебной власти, но и помогает установлению в обществе гармонии и социальной справедливости.

\section{Ссылки:}

1. Духовная культура Китая : энциклопедия : в 5 т. Т. 4: Историческая мысль. Политическая и правовая культура / ред. М.Л. Титаренко [и др.]. М., 2009. 935 с.

2. Pierre-E'tienne W. Developing Forensic Knowledge through Cases in the Qing Dynasty // Thinking with Cases: Specialist Knowledge in Chinese Cultural History / eds.: Ch. Furth, J.T. Zeitlin, P. Hsiung. Honolulu, 2007. P. 62-100. https://doi.org/10.1515/9780824865184-005.

3. Delporte D. Handbooks and Local Jurisdiction in Ming China. According to the Sections on Judicial Matters in the "Shihcheng lu" by Lü K'un, a Handbook for Magistrates // Crime, Histoire \& Sociétés = Crime, History \& Societies. 2002. Vol. 6, no. 2. P. 29-49. https://doi.org/10.4000/chs.412.

4. Миронов А.И. Судебная медицина Древнего Китая // Судебно-медицинская экспертиза. 1961. № 3. С. 44-48.

5. Hawes C. Reinterpreting Law in the Song: Zheng Ke's Commentary to the "Magic Mirror for Deciding Cases" // Journal of Asian Legal History. 2001. Vol. 1. P. 23-68.

6. Will P. Op. cit. P. 74.

7. Ibid. P. 89.

8. The "Hsi Yuan Lu" or "Instructions to Coroners". Translated from the Chinese by Herbert A. Giles, LL.D. Aberd, D. Litt. Oxon // Journal of the Royal Society of Medicine. 1924. Vol. 17. P. 59-107. https://doi.org/10.1177/003591572401701705.

9. Ibid. P. 77

10. Delporte D. Op. cit. P. 38

11. Ibid. P. 41-42

12. Karasawa Ya. From Oral Testimony to Written Records in Qing Legal Cases // Thinking with Cases ... P. 101-122. https://doi.org/10.1515/9780824865184-006.

13. Hawes C. Op. cit. P. 39-40.

14. Уголовные установления Тан с разъяснениями («Тан люй шу и»). Цзюани 26-30 / пер с кит. и коммент. В.М. Рыбакова. СПб., 2008. 416 с. 
15. Delporte D. Op. cit. P. 45

16. Hawes C. Op. cit. P. 44.

17. Ibid. P. 46-47.

18. Ibid. P. 48,53

19. Delporte D. Op. cit. P. $47-49$.

20. Хуан Сян. Судебные доказательства в гражданском процессе (опыт сравнительного правоведения на примере России и Китая). М., 2009. 96 с.

\section{References:}

Delporte, D 2002, 'Handbooks and Local Jurisdiction in Ming China. According to the Sections on Judicial Matters in the "Shihcheng lu" by Lü K'un, a Handbook for Magistrates', Crime, Histoire \& Sociétés = Crime, History \& Societies, vol. 6, no. 2, pp. 29-49, https://doi.org/10.4000/chs.412.

Giles, HA, Aberd, LLD \& Oxon, DLitt (trans.) 1924, 'The "Hsi Yuan Lu" or "Instructions to Coroners"', Journal of the Royal Society of Medicine, vol. 17, pp. 59-107, https://doi.org/10.1177/003591572401701705.

Hawes, C 2001, 'Reinterpreting Law in the Song: Zheng Ke's Commentary to the "Magic Mirror for Deciding Cases"', Journal of Asian Legal History, vol. 1, pp. 23-68.

Huang Xiang 2009, Evidence in Civil Proceedings (Comparative Law in Russia and China), Moscow, 96 p., (in Russian).

Karasawa, Ya 2007, 'From Oral Testimony to Written Records in Qing Legal Cases', in Ch Furth, JT Zeitlin, P Hsiung (eds), Thinking with Cases: Specialist Knowledge in Chinese Cultural History, Honolulu, pp. 101-122, https://doi.org/10.1515/9780824865184-006.

Mironov, Al 1961, 'Forensic Medicine of Ancient China', Sudebno-meditsinskaya ekspertiza, no. 3, pp. 44-48, (in Russian). Pierre-E'tienne, W 2007, 'Developing Forensic Knowledge through Cases in the Qing Dynasty', in Ch Furth, JT Zeitlin \& P Hsiung (eds), Thinking with Cases: Specialist Knowledge in Chinese Cultural History, Honolulu, pp. 62-100, https://doi.org/10.1515/9780824865184-005.

Rybakov, VM (trans.) 2008, Comments on Tang Dynasty Code (Tang lü shu yi). Juan 26-30, St. Petersburg, 416 p., (in Russian).

Titarenko, ML (ed.), et al. 2009, The Spiritual Culture of China: Encyclopedia, in 5 vols, vol. 4, Moscow, 935 p., (in Russian). 